\title{
Thermally Isolated Microstructures for Sensors and Actuators
}

\author{
Liwei Lin, Mu Chiao and Huey-Chi Chu \\ Institute of Applied Mechanics \\ National Taiwan University \\ Taipei, Taiwan, R.O.C.
}

\begin{abstract}
We have demonstrated the feasibility of thermal isolation by using suspended microstructures. Thermal insulation is provided by a suspension gap constructed by means of surface micromachining. Prototype line shape microstructures with a suspension gap of $2 \mu \mathrm{m}$ and length ranging from 10 to $100 \mu \mathrm{m}$, width ranging from 1 to 10 $\mu \mathrm{m}$ and thickness of $2 \mu \mathrm{m}$ have been fabricated and analyzed. Efficiencies of thermal isolation for these suspended microstructures are compared with two other microstructures, overhanging type made by bulk micromachining and attached type made by general IC process. The results show that suspended microstructures dissipate $\mathbf{8 0}$ times less heat than the attached type and 2 times more than the overhanging type microstructures when operated in air.
\end{abstract}

\section{NOMENCLATURE}

$\begin{array}{ll}c_{p} & =\text { specific heat of polysilicon. } \\ F_{s, a t t} & =\begin{array}{l}\text { excessive thermal conductive shape } \\ \text { factor of attached microstructures. }\end{array} \\ F_{s, s u s} & =\begin{array}{l}\text { excessive thermal conductive shape } \\ \text { factor of suspended microstructures. }\end{array} \\ h & =\text { thickness of a line shape microstructure. } \\ I & =\text { electrical current. } \\ J & =\text { electrical current density. } \\ k_{a t t} & =\text { combined thermal conductivity } \\ & \text { of attached microstructures. } \\ k_{f d} & =\text { thermal conductivity of working fluid. } \\ k_{s u s} & =\text { combined thermal conductivity } \\ k_{n} & =\text { of suspended microstructures. } \\ k_{o} & =\text { thermal conductivity of silicon nitride. } \\ k_{p} & =\text { thermal conductivity of polysilicon. } \\ k_{s} & =\text { thermal conductivity of silicon. } \\ L & =\text { length of a line shape microstructure. } \\ R & =\text { resistance of a line shape microstructure. }\end{array}$

\begin{tabular}{|c|c|c|}
\hline$T$ & $=$ & $\begin{array}{l}\text { temperature along a line shape } \\
\text { microstructure. }\end{array}$ \\
\hline$T_{s s, \max }$ & $=$ & $\begin{array}{l}\text { steady state maximum temperature on } \\
\text { a line shape microstructure. }\end{array}$ \\
\hline$T(x)_{s s}$ & $=$ & $\begin{array}{l}\text { steady state temperature along a line } \\
\text { shape microstructure. }\end{array}$ \\
\hline$T_{\text {avg }}$ & $=$ & $\begin{array}{l}\text { average temperature of a line } \\
\text { shape microstructure. }\end{array}$ \\
\hline$T_{r}$ & $=$ & $\begin{array}{l}\text { a reference temperature in } \\
\text { heat equation }\end{array}$ \\
\hline$T_{\infty}$ & $=$ & ambient (bulk) temperature. \\
\hline$t$ & $=$ & time. \\
\hline lift & $=$ & suspension distance. \\
\hline$t_{n}$ & $=$ & thickness of silicon nitride. \\
\hline$t_{o}$ & $=$ & thickness of silicon dioxide. \\
\hline$w$ & $=$ & width of a line shape microstructure. \\
\hline$x$ & $=$ & $\begin{array}{l}\text { coordinate along the length of a line } \\
\text { shape microstructure. }\end{array}$ \\
\hline$\alpha_{p}$ & $=$ & thermal diffusivity of polysilicon. \\
\hline$\epsilon$ & $=$ & $\begin{array}{l}\text { a combined variable term in heat } \\
\text { equation. }\end{array}$ \\
\hline$\rho_{0}$ & $=$ & $\begin{array}{l}\text { resistivity of polysilicon at room } \\
\text { temperature. }\end{array}$ \\
\hline$\rho_{p}$ & $=$ & density of polysilicon. \\
\hline$\xi_{p}$ & $=$ & $\begin{array}{l}\text { polysilicon temperature resistivity } \\
\text { coefficient. }\end{array}$ \\
\hline
\end{tabular}

\section{INTRODUCTION}

Thermal isolation is an important feature for microsystems sensitive to thermal response. For example, uncooled infrared detectors require good thermal isolation in order to detect tiny infrared radiation[1]. Bubble jet printers[2], on the other hand, would have consumed less power if thermally isolated microstructures were used for electrical heating. For traditional IC process, heating or sensing elements can only be made in attached to the substrate which results in poor thermal insulation and high power consumption. Previously, researchers have used 


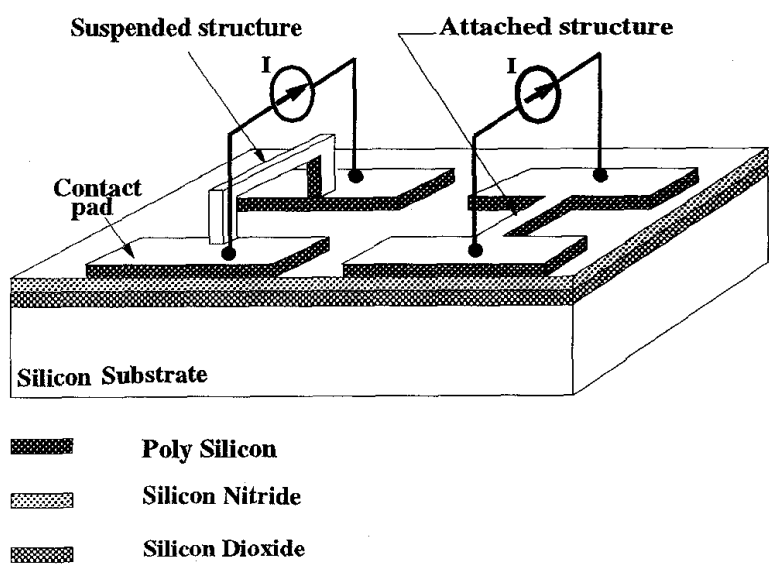

Figure 1: Schematic diagram of suspended and attached microstructures.

bulk micromachining to create overhanging microstructures $[3,4]$ for thermal isolation. However, since bulk micromachining creates holes at the back side of silicon wafer, it is not compatible in an ordinary IC foundry.

Recent developments in surface micromachining have demonstrated matured techniques for suspended micro structures on top of silicon substrate up to several $\mu \mathrm{m}$ in suspension distance [5]. This gap constructed between the suspended microstructure and substrate may provide enough thermal insulation for microsystems. Since surface micromachining is easier for IC integration, suspended micro structures may be excellent candidates as thermally isolated microstructures for sensors and actuators.

In order to determine the thermal isolation efficiency of suspended microstructures, detail thermal analysis is required. Previously, line shape microstructures in attached with substrate have been used to generate thermal bubbles for bubble powered microactuators [6]. Thermal analyses for these line shape micro structures have been investigated under both an open [7] and a micro shell environment [8]. Based on previous studies, this paper extends thermal analysis to suspended microstructures.

\section{THERMALLY ISOLATED MICROSTRUCTURES}

Line shape suspended microstructures are chosen for thermal isolation studies. They are easy to be fabricated and may be used as resistive heaters in applications like bubble jet printers. Figure 1 shows the schematic diagram of suspended and attached type microstructures which are made of $2 \mu \mathrm{m}$ thick heavily phosphorus doped polysilicon. The gap between substrate and the sus-

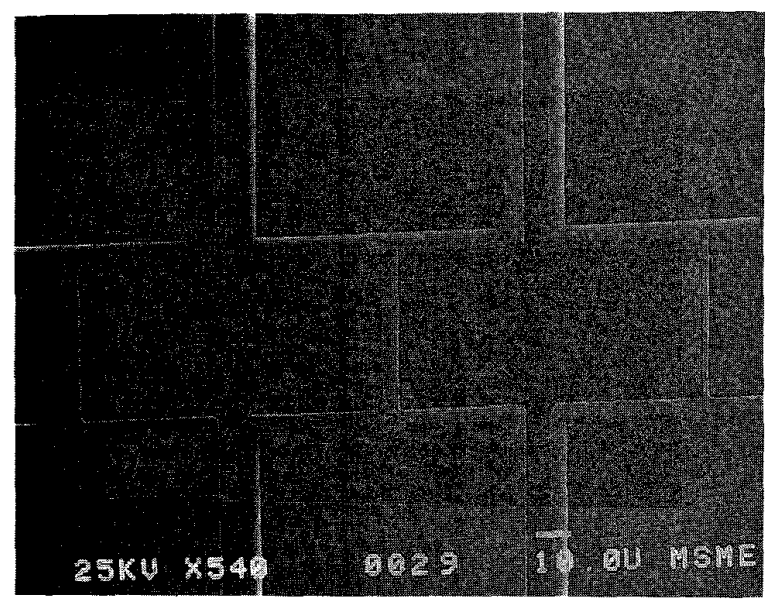

Figure 2: SEM micrograph of three line shape suspended microstructures with width of 10,5 and $2 \mu m$.

pended structure is $2 \mu \mathrm{m}$. Silicon nitride and oxide layers underneath the microstructure have thickness of 0.4 $\mu \mathrm{m}$ and $0.5 \mu \mathrm{m}$ respectively. Both layers function for electrical and thermal insulation. A current $I$ can be sent through contact pads to microstructures for electrical heating in order to control device temperatures.

Two sets of microstructures, one for suspended type and the other for attached type, have been fabricated by a standard surface micromachining process [5]. Each set has a group of line shape microstructures with length of 10,50 and $100 \mu \mathrm{m}$ and width of $1,2,5$ and $10 \mu \mathrm{m}$ differently. Figure 2 is a SEM micrograph of three suspended microstructures. They are $50 \mu \mathrm{m}$ long and 10 , 5 and $2 \mu \mathrm{m}$ wide (from left to right) respectively. Light color areas in the micrograph are suspended microstructures which stand $2 \mu \mathrm{m}$ above the substrate. Figure 3 is a SEM micrograph of attached type microstructures. They are $50 \mu \mathrm{m}$ long and $10,5,2$ and $1 \mu \mathrm{m}$ in width, respectively.

\section{THEORETICAL ANALYSIS}

\subsection{Heat equation}

A second order partial differential heat equation can be derived for these line shape microstructures based on the law of conservation of energy [9].

$$
\frac{\partial^{2} T}{\partial x^{2}}=\frac{1}{\alpha_{p}} \frac{\partial T}{\partial t}+\epsilon\left(T-T_{r}\right)
$$

in which $T$ is the temperature along the microstructure, $t$ stands for time, $\alpha_{p}$ is the thermal diffusivity of polysilicon and $\epsilon, T_{r}$ are parameters that are functions of structure dimension and thermal properties, as summerized below: 


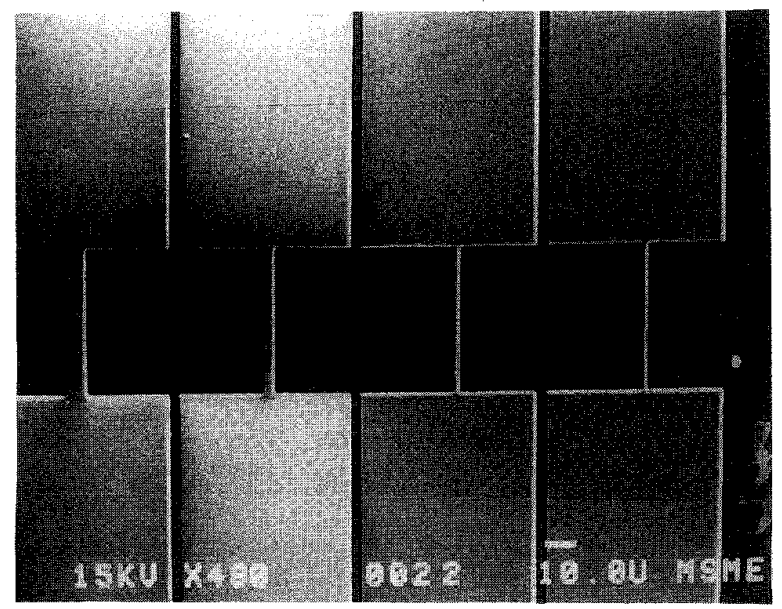

Figure 3: Fabricated attached type microstructures with width of $10,5,2$, and $1 \mu \mathrm{m}$.

- Attached microstructure

$$
\begin{gathered}
\alpha_{p}=\frac{k_{p}}{c_{p} \rho_{p}} \\
\epsilon=\frac{k_{a t t} F_{s, a t t}}{k_{p} h\left(t_{n}+t_{o}\right)}-\frac{J^{2} \rho_{o} \xi_{p}}{k_{p}} \\
T_{r}=\frac{k_{a t t} F_{s, a t t} T_{\infty}}{k_{p} h\left(t_{n}+t_{o}\right) \epsilon}+\frac{J^{2} \rho_{o}}{k_{p} \epsilon}-\frac{J^{2} \rho_{o} \xi_{p}}{k_{p} \epsilon}
\end{gathered}
$$

- Suspended microstructure

$$
\begin{gathered}
\alpha_{p}=\frac{k_{p}}{c_{p} \rho_{p}} \\
\epsilon=\frac{k_{s u s} F_{s, s u s}}{k_{p} h\left(t_{n}+t_{o}+l i f t\right)}-\frac{J^{2} \rho_{o} \xi_{p}}{k_{p}} \\
T_{r}=\frac{k_{s u s} F_{s, s u s} T_{\infty}}{k_{p} h\left(t_{n}+t_{o}+l i f t\right) \epsilon}+\frac{J^{2} \rho_{o}}{k_{p} \epsilon}-\frac{J^{2} \rho_{o} \xi_{p}}{k_{p} \epsilon}
\end{gathered}
$$

where $k_{\text {att }}$ and $k_{\text {sus }}$ are the combined thermal conductivity for attached and suspended microstructures respectively which can be expressed as:

$$
\begin{gathered}
k_{a t t}=\frac{k_{n} k_{o}\left(t_{n}+t_{o}\right)}{k_{o} t_{n}+k_{n} t_{o}} \\
k_{s u s}=\frac{k_{n} k_{o} k_{f d}\left(t_{n}+t_{o}+l i f t\right)}{k_{f d} k_{o} t_{n}+k_{f d} k_{n} t_{o}+k_{n} k_{o} l i f t}
\end{gathered}
$$

The excessive heat flux shape factor $F_{s, a t t}$ and $F_{s, s u s}$ for the attached and suspended microstructures are defined as:

$$
\begin{aligned}
F_{s, a t t} & =\frac{\text { total heat conduction per unit length }}{\frac{w k_{a t t}\left(T-T_{\infty}\right)}{t_{n}+t_{o}}} \\
F_{s, s u s} & =\frac{\text { total heat conduction per unit length }}{\frac{w k_{s u s}\left(T-T_{\infty}\right)}{t_{n}+t_{o}+l i f t}}
\end{aligned}
$$

A shape factor is defined as the total heat flux out of the line shape microstructure per unit length divided by the heat flux going directly under the width of the microstructure. For attached microstructures, the heat conducted to the substrate dominates the heat transfer process, but the heat conducted to the environment can also be included in the excessive flux shape factor term for accurate modeling. For suspended microstructures, the gap between the microstructure and the substrate results in a better thermal isolation, and the heat conducted to the substrate is no longer dominate. Thus the excessive flux shape factor becomes an important number to be determined.

\subsection{Steady state solution}

The steady state solution of the heat equation is solved subject to initial and boundary conditions by assuming that both ends of the line shape microstructure remain at the ambient temperature during the heating process and the microstructure is initially at the ambient temperature before heating. That is:

$$
\begin{aligned}
& T(x=0, t)=T_{\infty} \\
& T(x=L, t)=T_{\infty} \\
& T(x, t=0)=T_{\infty}
\end{aligned}
$$

The steady state solution of the temperature distribution along a line shape microstructure is:

$$
T(x)_{s s}=T_{r}-\left(T_{r}-T_{\infty}\right) \frac{\cosh \left[\sqrt{\epsilon}\left(x-\frac{L}{2}\right)\right]}{\cosh \left(\sqrt{\epsilon} \frac{L}{2}\right)}
$$

The maximum temperature can be derived from the steady state solution by differentiate the above equation, this gives:

$$
T_{s s, \text { max }}=T_{r}-\left(T_{r}-T_{\infty}\right) \frac{1}{\cosh \left(\sqrt{\epsilon} \frac{L}{2}\right)}
$$

It is noted in Eq. 16 that $T_{s s, \text { max }}$ depends on both $\epsilon$ and $T_{r}$. Since the electrical current density, $J$, is the only variable for both $\epsilon$ and $T_{r}, J$ can be solved if the desired maximum steady state temperature, $T_{s s, \text { max }}$, is specified. 


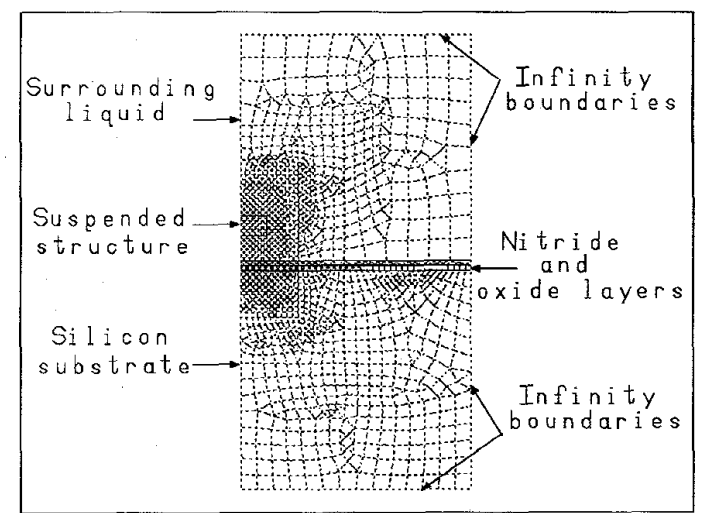

Figure 4: Finite element meshes for cross section of a line shape suspended microstructure. Only half structure is simulated.

\subsection{Electrical characteristics}

The electrical model including voltage and current can be found by deriving the resistance of a line shape microstructure. The resistance depends on temperature changes and can be calculated as:

$$
R=\int_{0}^{L} d R(T)=\frac{\rho_{o} L}{w h}\left[1+\xi_{p}\left(T_{a v g}-T_{\infty}\right)\right]
$$

where $T_{a v g}$ stands for the average temperature of the microstructure and can be expressed as:

$$
T_{\text {avg }}=\frac{1}{L} \int_{0}^{L} T d x=T_{r}-\left(T_{r}-T_{\infty}\right) \frac{\tanh \left(\sqrt{\epsilon} \frac{L}{2}\right)}{\sqrt{\epsilon} \frac{L}{2}}
$$

These equations are useful for calculating electrical power consumption.

\section{NUMERICAL SIMULATIONS}

\subsection{Shape factor}

A finite element simulation package, ANSYS [10], is used to calculate steady state heat transfer characteristics. There are about two thousand meshes in the cross section region of a suspended microstructure as shown in Fig. 4. Only half of the structure which is $4 \mu \mathrm{m}$ wide and $2 \mu \mathrm{m}$ thick is simulated due to symmetry. Infinity boundaries which are provided with the software package are used to assure simulation accuracy.

Figure 5 and Figure 6 are finite element simulation results of isotherms for suspended and attached microstructures. In both cases, microstructures are immersed in water and heated to a high temperature. It is observed that major heat transfer process occurs in a very small

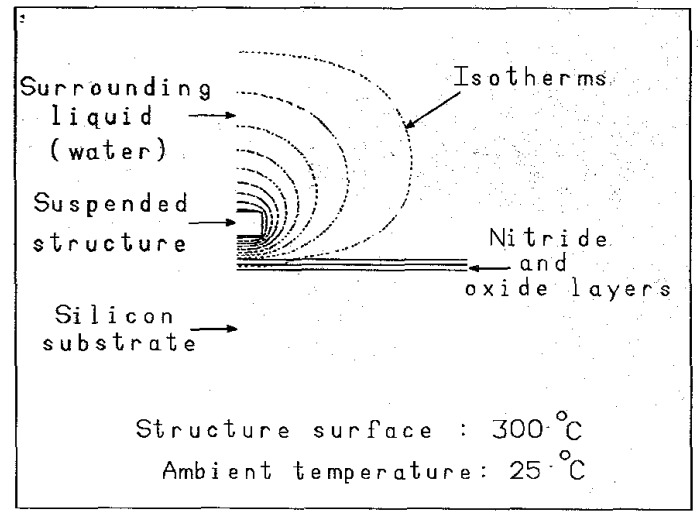

Figure 5: Isotherms of a suspended microstructure which is $4 \mu \mathrm{m}$ wide, $2 \mu \mathrm{m}$ thick and $2 \mu \mathrm{m}$ suspended above substrate.

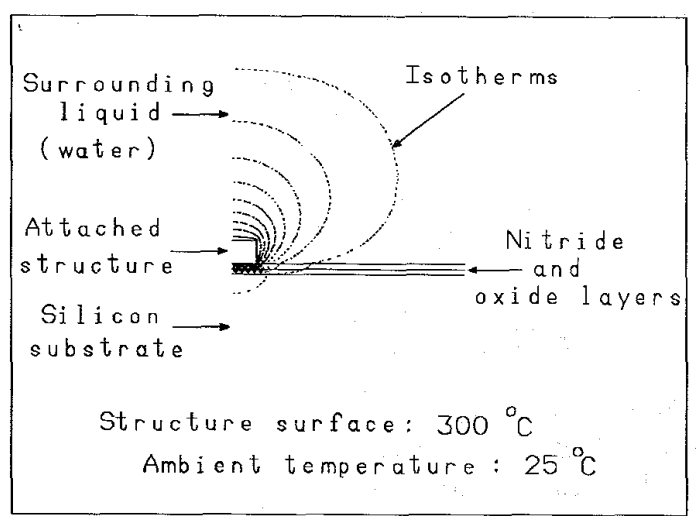

Figure 6: Isotherms of an attached microstructure which is $4 \mu \mathrm{m}$ wide and $2 \mu \mathrm{m}$ thick. 


\begin{tabular}{||c|c|c|c||}
\hline Heat fluxes $\left(10^{6} \frac{\text { Joule }}{\mathrm{m}^{2}}\right)$ & $\mathrm{FC72}$ & air & water \\
\hline Suspended structure & 6.83 & 3.00 & 65.73 \\
\hline Attached structure & 238.36 & 236.20 & 273.32 \\
\hline Overhanging structure & 3.30 & 1.52 & 33.93 \\
\hline
\end{tabular}

Table 1: Heat fluxes from cross section of three different types of microstructures which are heated at $300^{\circ} \mathrm{C}$

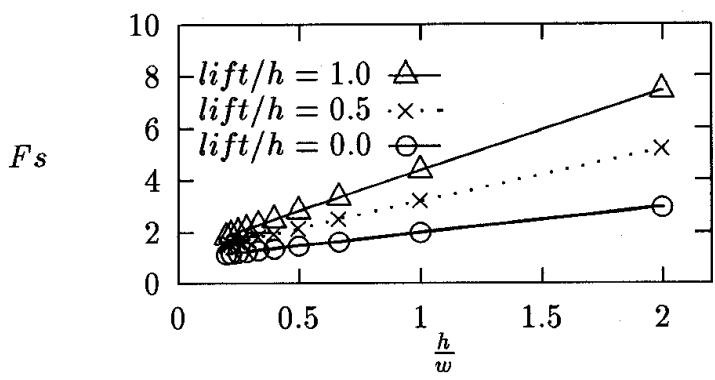

Figure 7: Shape factor versus $\frac{h}{w}$ for different types of microstructures.

region around the microstructure for both cases. For the attached type microstructure, rapid temperature change occurs in the passivation layers underneath it.

Results from finite element simulation are used in calculating shape factors which affect overall heat transfer process. Structures with different cross sections and suspension gaps have been simulated. Figure 7 shows $F_{s}$ plotted with respect to a nondimensional variable $\frac{h}{w}$ (thickness of the line shape microstructure over its width). Three cases, $\frac{\text { lift }}{h}=0, \frac{\text { lift }}{h}=0.5$, and $\frac{\text { lift }}{h}=1$, have been simulated with the thickness of microstructures being fixed at $2 \mu \mathrm{m}$. As expected, $F_{s}$ increases as $\frac{h}{w}$ increases since heat transfer to the environment becomes more dominant. It is also observed that if $\frac{h}{w}$ is fixed, the higher the suspension distance, the larger the shape factor. This implies that as the suspension gap becomes lager, more heat is dissipated to surrounding environment than to the substrate proportionally. Interestingly, $F_{s}$ seems to be linearly increasing with respect to $\frac{h}{w}$. Slopes of these lines are found to be $1.00,2.06$ and 3.12 respectively. Moreover, as $\frac{h}{w}$ approach zero, shape factors approach 1 for all three cases.

\subsection{Heat flux and power consumption}

In many applications, it may be desired to maintain sensors or actuators at a fixed temperature and it is interesting to know the power consumption. One application for these suspended microstructures is to generate thermal bubbles at around $300^{\circ} \mathrm{C}$ for bubble powered microactuators [6]. Hence, this particular temperature is used for all quantitative calculations in this paper.

In order to compare thermal isolation efficiencies of different microstructures, cross sectional heat fluxes are simulated with respect to different liquids as listed in Table 1. Dimensions for these simulated microstructures are $4 \mu \mathrm{m}$ in width and $2 \mu \mathrm{m}$ in thickness and the suspension distance is $2 \mu \mathrm{m}$. It is observed that heat fluxes for suspended microstructures are 35, 80 and 4 times less than those of attached ones in FC 72 (an electronic cooling liquid from $3 \mathrm{M}$ company), air and water, respectively. This demonstrates that suspended microstructures provide better thermal insulation than attached ones especially in air. Furthermore, heat fluxes for suspended microstructures are about twice as large as overhanging microstructures for all cases of fluids. This implies that suspended microstructures may replace overhanging microstructures in most applications.

The power consumption rate can be calculated to evaluate the device performance. Once a specific temperature is given, Eq. 16 is solved by Newton method to obtain current density, $J$. Resistance, $R$, is then calculated by using Eq. 17 and Eq. 18 to obtain electrical power. Figure 8 shows the electrical power consumption with respect to length of suspended and attached microstructures. Both types of microstructures simulated have cross section of $4 \mu \mathrm{m}$ in width and $2 \mu \mathrm{m}$ in thickness and the suspension distance is $2 \mu \mathrm{m}$. It is observed that only about $50 \mathrm{mWatt}$ of power is needed for line shape suspended microstructures with length up to 100 $\mu \mathrm{m}$. However, power consumption reaches $300 \mathrm{mWatt}$ as the length of attached microstructures is longer than 100 $\mu \mathrm{m}$.

\section{DISCUSSIONS}

The nondimensional shape factors calculated in Fig. 7 can be applied to all microstructures with dimensions being proportionally magnified. However, it would be interested to know shape factors variations with fixed passivation layers. Figure 9 shows two groups of shape factors simulated with fixed passivation layers dimensions which are $0.4 \mu \mathrm{m}$ for nitride and $0.5 \mu \mathrm{m}$ for oxide. The solid lines are two suspended microstructures with fixed $\frac{l i f t}{h}=1$ ratio and the dash lines are two attached microstructures. The symbol $\times$ represents data for $h=1 \mu \mathrm{m}$ and the symbol $\Delta$ represents data for $h=2 \mu \mathrm{m}$. In the group of suspended microstructures (solid lines), shape factors follow each other while a maximum deviation of about $8 \%$ occurs at $\frac{h}{w}=2$. However, in the group of attached microstructures, the shape fac- 


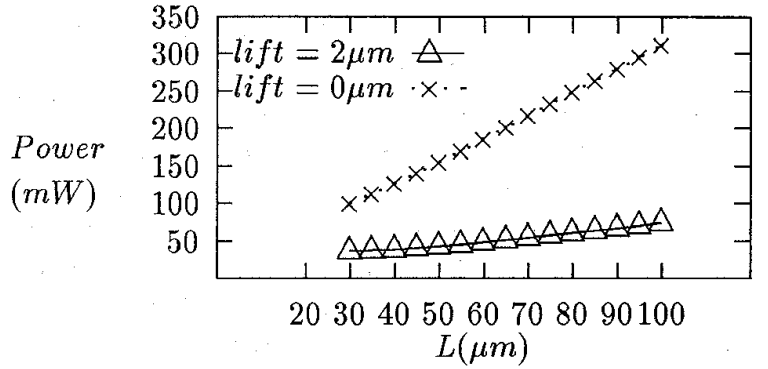

Figure 8: Power consumption versus structure length for line shape microstructures which have cross section of 4 $\mu \mathrm{m}$ in width and $2 \mu \mathrm{m}$ in thickness.

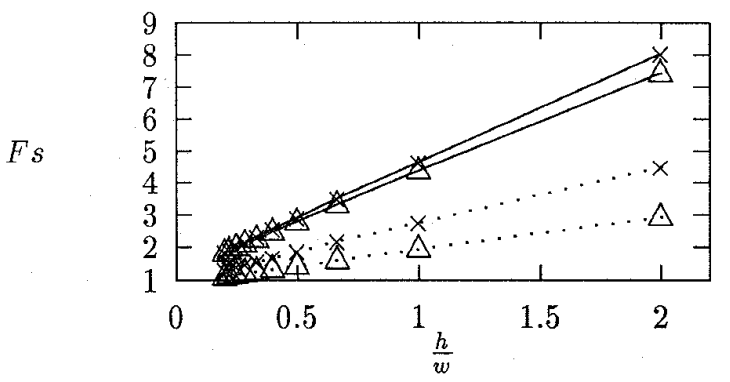

Figure 9: Variation of shape factors under fixed passivation layers. Solid lines are suspended microstructures with $\frac{\text { lift }}{h}=1$ and dash lines are attached microstructures. The $\times$ symbol represents shape factors for $h=1 \mu \mathrm{m}$ and the $\Delta$ symbol represents shape factors for $h=2 \mu \mathrm{m}$.

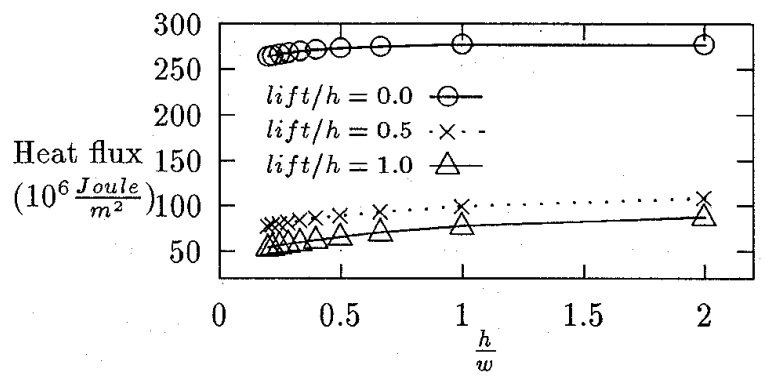

Figure 10: Comparison of heat fluxes with respect to $\frac{h}{w}$. All the microstructures have thickness of $2 \mu \mathrm{m}$. tors have large deviation which reach $54 \%$ at $\frac{h}{w}=2$. In both cases, shape factors of $h=1$ are large than those of $h=1$ microstructures. From the above simulation, we conclude that new simulation is necessary for new structural dimensions for accurate modeling.

Figure 10 is the comparison of heat fluxes for suspended and attached microstructures immersed in water. There are three lines, suspended microstructures with 2 and $1 \mu \mathrm{m}$ suspension distance and attached type microstructures. It is observed that suspended microstructures have less heat fluxes than attached ones. The heat fluxes may be further decreased if a higher suspension distance is used. In all cases, the heat fluxes seem to be very close for all $\frac{h}{w}$ values and increase little as $\frac{h}{w}$ increases.

Finally, heat transfer through contact pads may not be neglected, especially for the regions near contact pads. This effect has not been addressed in our model. If the overall structure length is long and portions of interest are far away from contact pads, analysis developed in this paper would be valid. However, for short structures or regions near contact pads, detailed heat transfer analysis needs to be further investigated.

\section{CONCLUSION}

Suspended line shape microstructures have been demonstrated to function as thermally isolated microstructures. Theoretical analysis shows that they dissipate 80 times less heat than the attached type microstructures in air environment. Thermal models have been established for both attached and suspended line shape microstructures. Nondimensional heat transfer shape factors have been evaluated for the thermal modeling. It is concluded that these shape factors are linearly proportional to the device thickness over width, $\frac{h}{w}$, ratio and approach 1 as $\frac{h}{w}$ approach zero.

\section{References}

[1] L. Pham, W. Tjhen C. Ye and D.L. Polla, Surfacemicromachined Pyroelectric Infrared Imaging Array with Vertically Integrated Signal Processing Circuitry, IEEE Transactions on Ultrasonics, Ferroelectrics and Frequency Control, Vol. 41, pp. 552$555,1994$.

[2] R.R. Allen, J.D. Meyer and W.R. Knight, Thermodynamics and Hydrodynamics of Thermal Ink Jets, HP Journal, Vol. 36, No. 5 pp. 21-27, 1985.

[3] G.R. Lahiji and K.D. Wise, A batch-fabricated silicon thermal infrared detector, IEEE Transactions on Electron Devices, Vol. ED-29, No. 1, 1982. 
[4] Jin-Shown and Ping Kuo Weng, Fabrication of micro-bolometer on silicon substrate by anisotropic etching technique, International conference on solidstate sensors and actuators, pp. 627-630, 1991.

[5] W.C. Tang, T.H. Nguyen, M.W. Judy and R.T. Howe, Electrostatic-comb drive of lateral polysilicon resonators, Sensors and Actuators, A: Physical Vol 21, No. 1-3, pp. 328-331, 1990.

[6] Liwei Lin and A.P. Pisano, Thermal bubble powered microactuators, Microsystem Technologies, Vol. 1, pp. 51-58, 1994

[7] Liwei Lin and A.P. Pisano, Bubble forming on a micro line heater, American Society of Mechanical Engineers, Dynamic Systems and Control Division DSC Vol. 32, pp. 147-163, 1991.

[8] Liwei Lin, K. S. Udell and A. P. Pisano, Phase Change Phenomena on a Heated Polysilicon Micro Heater in Confined and Unconfined Micro Channels, Thermal Sciences and Engineering, Vol. 2, No. 1, pp. 52-59, 1994.

[9] Liwei Lin, Doctorial dissertation, Department of Mechanical Engineering, University of California, Berkely.

[10] Swanson Analysis Systems, Inc., ANSYS Finite Element Analysis Program Johnson Road, P.O. Box 65, Houston, PA, 15342-0065, USA. 